\title{
Do Genetic Factors Influence Religious Life? Findings from a Behavior Genetic Analysis of Twin Siblings
}

\author{
MATT BRADSHAW \\ CHRISTOPHER G. ELLISON
}

\begin{abstract}
Social scientific research assumes that religious involvement is primarily, if not exclusively, the product of socialenvironmental influences. There is growing evidence, however, that genetic or other biological factors also play a role. Analyzing twin sibling data from the National Survey of Midlife Development in the United States (MIDUS), this study addresses this issue by showing that individual-level variation on four different aspects of religious lifeorganizational involvement, personal religiosity and spirituality, conservative ideologies, and transformations and commitments-is indeed the product of both genetic and environmental influences. Specifically, genetic factors explain 19-65 percent of the variation, while environmental influences account for the remaining 35-81 percent depending upon the aspect of religion under investigation. Research of this type enhances contemporary social science by providing a new perspective that nicely supplements existing ones, but it also highlights potential implications, including explanatory power deficiencies and potentially bias.
\end{abstract}

\section{INTRODUCTION}

Social scientific research assumes that religious involvement is primarily, if not exclusively, the product of social-environmental influences-for example, observational learning, positive and negative reinforcement, normative and cultural pressures, social exchanges, etc. (Batson, Schoenrade, and Ventis 1993; Ellison and Sherkat 1995; Hayes and Pittelkow 1993; Myers 1996; Sherkat 1997; Smith 2003; Stark and Finke 2000). There is growing evidence, however, that this assumption is false, and that genetic or other biological factors also influence religious life.

For example, a handful of twin and adoption studies have reported statistically significant genetic effects on several religious outcomes, including service attendance, conservative beliefs, and spirituality, among others (Beer, Arnold, and Loehlin 1998; D'Onofrio et al. 1999; Kirk, Eaves, and Martin 1999; Koenig et al. 2005; Loehlin and Nichols 1976; Winter et al. 1999). In addition, Miller and Stark (2002) recently invoked biology as a potential explanation for one of the most replicated findings in the literature: the fact that women are, on average, more religious than men. Further, while critiquing the arguments of sociobiology and evolutionary psychology, Smith (2003:38-39) nonetheless acknowledged that biological factors play some sort of role in the construction of "moral (i.e., religious), believing animals":

Rejecting the reductionism of explaining human morality as serving the interests of selfish genes, however, does not require the dismissal of an interest in biological factors in human social life. Nor does it necessitate the rejection of possible evolutionary frameworks of explanation. In whatever other ways that human animals may be

Matt Bradshaw received his Ph.D. in Sociology from the University of Texas at Austin and is currently a Postdoctoral Fellow in the Carolina Population Center at the University of North Carolina at Chapel Hill, NC. E-mail: drmattbradshaw@yahoo.com

Christopher G. Ellison is a Professor of Sociology in the Department of Sociology at the University of Texas at Austin, TX. E-mail: cellison@prc.utexas.edu

Correspondence should be addressed to Dr. Matt Bradshaw, Carolina Population Center, The University of North Carolina at Chapel Hill, University Square, CB\# 8120, 123 W. Franklin St., Chapel Hill, NC 27516-3997; 817-946-1165. E-mail:drmattbradshaw@yahoo.com 
mental or moral or spiritual beings, we are also clearly biological organisms, and there is no reason to think that biology and mental, moral, and spiritual life do not interact. Of course they do.

Focusing on one particular biological influence—genetic similarities/differences—-this study extends our knowledge on this front by addressing an elemental question: Is individual-level religious variation the product of both genetic and environmental influences, and if so, what is the relative contribution of each? ${ }^{1}$ If religious involvement is indeed influenced by genetic factors, traditional social scientific models may suffer from explanatory power deficiencies if they ignore sizable genetic effects. Furthermore, studies employing religious participation as a predictor of other outcomes such as prosocial attitudes and behaviors, family relations, and health and wellbeing, among others, may report findings that are biased by latent genetic influences (Bouchard and Loehlin 2001). Thus, it is crucial that we determine whether, and to what extent, genetic factors influence religious life.

This study does this by initially reviewing the small, but growing, literature in this area. The theory, methods, and statistical techniques used to conduct genetically informed research on religious involvement will then be described. Analyzing data from the National Survey of Midlife Development in the United States (MIDUS) — a large national sample of working-age (2574) twin siblings - genetic and environmental influences on individual-level religious variation will then be estimated for four unique aspects (eight measures) of religious life: organizational involvement, personal religiosity and spirituality, conservative ideologies, and transformations and commitments. A detailed discussion of the relevance of these findings for the social scientific study of religion will then be provided, and the study will conclude by outlining an agenda for future research.

\section{BACKGROUND}

In support of the widely held assumption that religion is a social phenomenon, research has shown that individual differences in religious involvement are influenced by an array of environmental factors, including parental religiosity and moral emphasis (Francis and Brown 1991; Hayes and Pittelkow 1993; Hoge, Petrillo, and Smith 1982; Myers 1996), school and church settings (Francis and Brown 1991; Regnerus, Smith, and Smith 2004), community and cultural contexts (Berger 1969; Ellison and Sherkat 1995; Geertz 1973; Pattillo-McCoy 1998; Smith 2003; Wuthnow 1989), and even religious market structures (Finke and Stark 1992; Iannaccone 1994; Stark 1996; Stark and Bainbridge 1996; Stark and Finke 2000). Although the utility of this literature is undeniable, a potential problem exists: religious socialization occurs primarily in family contexts, and family members share both genes and social environments.

It is therefore imperative that we begin to examine (a) whether, and to what extent, genetic factors influence individual-level variation on religious outcomes, and (b) if the relative contribution of genetic and social-environmental influences varies depending upon the aspect of religious life under consideration (i.e., whether genetic influences are more important for some religious outcomes compared with others). An approach referred to as behavior genetics provides the theoretical, methodological, and statistical tools required to investigate these issues (Carson and Rothstein 1999; Plomin and Rende 1991). Specifically, by simultaneously analyzing data on two or more family members with varying degrees of genetic relatedness (e.g., identical vs. fraternal twin pairs, biological vs. adopted siblings, etc.), behavior genetic techniques allow researchers to decompose observed (i.e., phenotypic) individual-level variation on any outcome, including religious ones, into three proportional variance components: genetic, shared environmental, and nonshared environmental influences (Neale and Cardon 1992; Plomin 1990).

Within this framework, genetic influences gauge the effects of biologically inherited individual differences in DNA and related products (e.g., proteins, hormones, anatomical structures, etc.). 
When applied to "social" outcomes such as religious involvement, genetic influences-which function to make individuals who share them similar to each other-tell us what proportion of the variation among individuals is explained by gene-based predispositions, needs, wants, desires, or motivations. In other words, the genetic component of the behavior genetic model is perhaps best conceptualized as an indicator of, or a proxy for, the manifestation of innate attitudinal and behavioral orientations (Udry 1996).

Shared environmental influences in the behavior genetic framework are nongenetic, familylevel social influences that are common to individuals in a family unit, perfectly correlated between them, and that function to make those who share them similar to each other. In most cases, this reflects the influence of parents and siblings, but it also gauges other factors such as shared friends, teachers, religious leaders, family socioeconomic status, and even certain cultural or ecological influences, such as living in a religiously homogeneous community. In essence, this component of the behavior genetic model taps the effects of family-level socialization as conceptualized by most social scientific theories, and thus it is of crucial importance to scholars in this area.

Nonshared environmental influences, in contrast to shared ones, are environmental sources of variation that are unique to individuals, uncorrelated between them, and that function to make individuals different from one another. This is a heterogeneous residual category that contains not only environmental influences that are not shared by individuals - that is, different friends, role models, interpretations of culture, opportunities, etc.—but also measurement error in empirical analyses. Unlike shared genes and shared environmental influences, which both function to increase family similarity, nonshared environmental influences or unique experiences function to differentiate individuals. ${ }^{2}$

Although still relatively sparse, behavior genetic research has actually been conducted on religious involvement, and the current literature suggests three broad trends. First, religious affiliation appears to be transmitted primarily via social and cultural mechanisms (e.g., familybased socialization, normative pressures, memes, etc.), not genetic ones (Boomsma et al. 1999; Eaves, Martin, and Heath 1990). That said, at least one study has reported a small genetic effect on being a member of a conservative religious institution (12 percent), but the majority of the variation on this outcome was nonetheless shown to be the product of shared (51 percent) and nonshared (37 percent) environmental influences (Kendler, Gardner, and Prescott 1997).

Second, several behavior genetic studies have examined organizational religious involvement (i.e., religious or spiritual service attendance), but the results to date have been somewhat inconsistent. For example, while one study found no support for genetic influences on individual-level variation on religious attendance (Truett et al. 1992), other publications have reported statistically significant genetic effects on this outcome (Kendler, Gardner, and Prescott 1997; Kirk et al. 1999). Further, in a recent article genetic factors were found to account for 39 percent of the variation on an indexed measure of "external religiousness" that included items tapping service attendance, discussing religious teachings, observing religious holidays, and membership in youth/study groups (Koenig et al. 2005). Given these somewhat contradictory findings, additional research will be required before we will be able to confidently make any conclusions regarding the presence, or absence, of genetic effects on this aspect of religious life. ${ }^{3}$

Third, researchers have also explored an assortment of religious beliefs and attitudes, again with somewhat mixed findings. For example, a few studies have reported that genetic factors account for a significant proportion (20-45 percent) of the individual-level variation on fundamentalist orientations (Beer, Arnold, and Loehlin 1998), as well as attitudes pertaining to the observance of the Sabbath, divine law, church authority, and the truthfulness of the Bible, among others (Martin et al. 1986). Another published manuscript, however, found virtually no genetic contribution to individual variation on personal conservatism (Kendler, Gardner, and Prescott 1997). Meanwhile, a recent study of "internal religiousness" found that genetic factors accounted for 34 percent of the variation (Koenig et al. 2005). An article on intrinsic and extrinsic 
religious motivations reported that slightly more than a third of the individual variation on each was due to genetic differences (Bouchard et al. 1999), while a study of self-transcendence found that genetic influences explained approximately 40 percent of the variation (Kirk, Eaves, and Martin 1999). Genetic factors even appear to influence attitudes concerning religious leisure time and occupational interests (Waller et al. 1990).

Overall this literature, while thought provoking, suffers from several shortcomings, including inconsistent findings and the lack of detailed information regarding the presence and size of genetic effects on a variety of theoretically important and widely employed (by social scientists) aspects of religious life such as personal religious salience, religious coping strategies, the use of religion during daily life, fundamentalist beliefs, and religious transformations and commitments. To date, only religious affiliation, service attendance, and a handful of beliefs and attitudes have been examined from a behavior genetic perspective, and even in these areas, more research is needed because contradictory results have been reported. Furthermore, very few of the published findings in these areas have been replicated, and certainly not with populationbased, national data. Therefore, by analyzing data on numerous aspects of religious life drawn from a large sample of U.S. adults, this study addresses many of these shortcomings in the literature.

\section{Methods}

\section{Data}

In order to examine genetic and environmental influences on individual-level religious variation, this study analyzes twin sibling data from the MIDUS, 1995-1996, which were obtained via the Inter-University Consortium for Political and Social Research (ICPSR) (Brim et al. 1996, 2003). These data were collected on working-age (25-74) adults to examine the patterns, predictors, and consequences of midlife development in the areas of physical health, psychological well-being, and social responsibility, among others. This particular data source was selected for this study for three reasons. First, it includes questions gauging numerous aspects of religious life, including several that have yet to be examined with genetically informed techniques. Second, it contains data on adults, which is especially important since theory suggests that genetic influences should manifest themselves more strongly among adults because they have more freedom to make choices compared with children and adolescents (D'Onofrio et al. 1999; Plomin 1990; Udry 1996). And third, it is a large national sample, which will make the results more generalizable to the U.S. population than previous research on this topic.

Two data collection agencies (ICR/AUS Consultants and Bruskin Associates) were hired by MIDUS personnel to recruit twin pairs by making telephone calls and asking respondents whether they, or any of their immediate family, were members of an intact twin pair. Roughly 50,000 households, constituting a representative sample of the United States, were screened in this manner. Respondents who reported the presence of a twin in the family (14.8 percent) were then asked if they would allow the research team to contact them again to solicit their participation in the survey. The 60 percent of the respondents who agreed were then referred to the MIDUS recruitment process. The twin pairs that ultimately participated in the MIDUS Twin Screening Project represent the first national sample of twin pairs ascertained randomly via the telephone (for additional information on the sample or sampling process, see Brim et al. [1996] 2003).

Twin pairs were diagnosed as monozygotic (i.e., identical) versus dizygotic (i.e., fraternal) with self-report data on whether they had (a) the same eye color, (b) natural hair color, (c) complexion, (d) whether they were mistaken for each other when they were young, and (e) whether they had ever undergone testing or been told by a doctor whether they were genetically identical 
or fraternal. Pairs were given a series of points for their answers to these specific questions and the points were subsequently totaled. High scores indicated identical twin pairs while low scores indicated fraternal twin pairs. Similar methods of diagnosing zygosity have been shown to be over 90 percent accurate (Lykken et al. 1990; Maes et al. 1999). The scores of 26 pairs fell directly in the middle of the range, making a definitive classification impossible. These pairs, along with all opposite-sex dizygotic twin siblings, were excluded from this study. The findings reported here are based on 193-316 pairs of monozygotic siblings (note: $N$ s vary depending upon the particular aspect of religion under investigation) and 176-278 pairs of same-sex dizygotic siblings.

\section{Measures}

The MIDUS data contain measures of four distinct aspects of religious life. Organizational involvement is gauged with a single-item tapping the frequency of attendance at religious services. Respondents were asked: "In a typical month, about how many times do you attend religious services?" A handful of respondents reported attending at very high rates (i.e., 20 or more times per month). Given that this seems improbable, if not impossible, responses above the 95th percentile are recoded to equal the mean. Ancillary analyses revealed that this did not alter the findings reported here. The range on the recoded variable is $0-11$, and due to the skewed nature of this measure even after this recoding, a square root transformation is performed in order to normalize the distribution.

Four different measures are used to gauge personal religiosity and spirituality. Childhood religiosity is tapped with the following retrospective question (coded $1=$ not at all to $4=$ very much): "How important was religion in your home when you were growing up?" Religious salience is a six-item summed index (Cronbach's alpha $=0.88$; each item is coded $1=$ not at all to $4=$ very). Specific items include: (a) "How religious are you?" (b) "How important is religion in your life?" (c) "How important is it for you-or would it be if you had children now-to send your children for religious or spiritual services for instruction?" (d) "How closely do you identify with being a member of your religion?" (e) "How much do you prefer to be with other people who are the same religion as you?" and (f) "How important do you think it is for people of your religion to marry people who are the same religion?" Spirituality is gauged with two items (alpha $=0.91$; each item is coded $1=$ not at all to $4=$ very): (a) "How spiritual are you?" and (b) "How important is spirituality in your life?" Daily guidance and coping is tapped with two questions (alpha $=0.85$; each is coded $1=$ never to $4=$ often): (a) "When you have decisions to make in your daily life, how often do you ask yourself what your religious or spiritual beliefs suggest you should do?" and (b) "How often do you seek comfort through religious or spiritual means such as praying, meditating, attending a religious or spiritual service, or talking to a religious or spiritual advisor?"

Conservative ideologies are gauged with two single-item measures. Biblical literalism, a commonly employed measure of religious conservatism, is tapped with the following question: "How much do you agree or disagree with the following statement (coded $1=$ strongly disagree to $5=$ strongly agree): "The Bible is the actual Word of God and is to be taken literally, word for word?" Exclusivist beliefs are measured with the following question (coded $1=$ yes and $0=$ no): "Do you believe that one should: stick to one faith?" For this variable, respondents who answered "yes" are compared with those who believed that individuals should "explore different teachings," do "neither" of these things, or "don't know" the answer to this question.

Transformations and commitments are measured with the following question (coded $1=$ yes and $0=$ no): "Have you been 'born-again,' that is, had a turning point in your life when you committed yourself to Jesus Christ?" 


\section{FIGURE 1 \\ UNIVARIATE STRUCTURAL EQUATIONS MODEL}

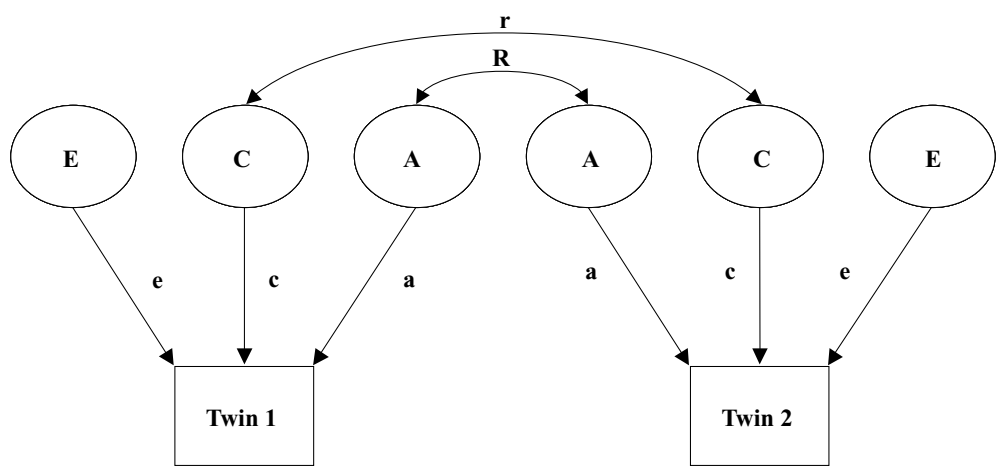

Notes: Circles represent latent (unmeasured) variables and squares represent manifest (measured) variables; $\mathrm{A}=$ additive genetic factor; $\mathrm{C}=$ shared environmental factor; $\mathrm{E}=$ nonshared environmental factor; $\mathrm{R}=$ genetic relatedness ( 1.0 for monozygotic twins and 0.5 for same-sex dizygotic twins); and $\mathrm{r}=$ twin sibling environmental exposure (1.0 for both types of twins).

\section{Behavior Genetic Methods, Twin Studies, and Structural Equations Modeling (SEM)}

This study employs a classical twin design. In analyses utilizing twin sibling data, one twin is correlated with their sibling separately for monozygotic and dizygotic twins. These intrapair correlations are then compared across the two types of twins. If monozygotic siblings are more highly correlated with (i.e., more similar to) each other than dizygotic twins, genetic influences are implied. The logic behind this rests on the assumption that no substantive differences exist in the environments of monozygotic versus dizygotic twins. Therefore, if monozygotic siblings are more highly correlated with each other than dizygotic ones despite living in similar environments, shared genetic predispositions must be responsible. If the intrapair correlations are similar for the two types of twins, shared environmental influences are implied. The logic behind this rests on the assumption that the only influence other than shared genes that is capable of producing similarities among twin siblings is shared environments or common experiences. Thus, if both groups are similarly correlated, yet not that similar genetically, shared environmental influences must be contributing to twin similarities. If the correlations for both groups are relatively low, nonshared environmental influences are implied. The logic behind this rests on the assumption that unique experiences function to differentiate individuals. Overall, using these assumptions and correlations, along with the statistical techniques described below, it is possible to estimate the proportion of individual-level variation on any religious outcome that is due to genetic, shared environmental, and nonshared environmental influences.

SEM is the most precise and widely employed method for estimating twin models. In the terminology of SEM, twin designs are two-population models composed of monozygotic and dizygotic twin pairs. In structural models like the one shown in Figure 1, the correlation between monozygotic siblings is fixed to 1.0 on the genetic factor because these siblings are, by definition, genetically identical (i.e., they are perfectly correlated with each other genetically). The correlation between dizygotic twin siblings, in contrast, is fixed to 0.5 on the genetic factor because they share, on average, half their genes. Shared environmental influences are contexts that twin siblings have in common regardless of zygosity, so this factor is fixed to 1.0 for both types of twins. Nonshared environmental influences, on the other hand, are contexts that are unique to each twin of a pair, which means that there is no correlation between siblings on this factor for either monozygotic or dizygotic twins. 
Using the publicly available SEM package Mx (Neale et al. 2003), the following three structural models are fit to the data (using maximum likelihood analysis of variance-covariance matrices) for each of the eight religion measures (separately): a full model that decomposes observed individual-level variation into latent genetic, shared environmental, and nonshared environmental components; a reduced model that drops the shared environmental component; and a reduced model that drops the genetic component. Estimating a nonshared-environment-only model would assume that there is no family resemblance on these religious outcomes, and that twins are not correlated. This is obviously not the case, so this model is not estimated for any of the measures employed here. Additionally, models that do not contain a nonshared environmental component are not estimated because they would assume that that no differences exist between monozygotic twin siblings (i.e., that monozygotic siblings are perfectly correlated with each other). This is also clearly false.

Model fit for each of the three models is assessed using the $-2 \log$ likelihood (-2LL), chisquare $p$-value, and Akaike's Information Criterion (AIC $=\chi^{2}-2 d f$ ). To test for the statistical significance of the parameters in the full model (genetic and shared environmental influences only), both of the reduced models (i.e., genetic and nonshared environmental factors only, and shared and nonshared environmental factors only) are compared with the full model (separately) using likelihood ratio tests. Since the resulting test is symtotically distributed as a chi-square, the change in fit between the models can be calculated by taking the difference in -2LL, with degrees of freedom being equal to the difference in the number of parameters estimated in the full versus reduced model. A nonsignificant change in chi-square test indicates that the reduced model is a better fit to the data, and that the dropped parameter (either the genetic or shared environmental factor) is therefore not statistically significant. Additionally, 95 percent confidence intervals for each of the three parameters in the full model are also computed as an alternate check of statistical significance.

To obtain proportional estimates of the effects of the three latent factors in the structural model (Figure 1), three steps are required. First, each of the path estimates $(a, c$, and $e)$ is squared. Second, the three squared path estimates are then added together. And third, each individual squared path estimate is then divided by the sum-total of all three of the squared path estimates to obtain a proportional estimate for each path. Once calculated, these estimates provide information on the proportion of individual-level variation on any outcome that is explained by genetic $(A)$, shared environmental $(C)$, and nonshared environmental $(E)$ influences (for additional details on twin studies, SEM, fit statistics, or the ACE model, see Cleveland and Crosnoe 2004; Neale and Cardon 1992; Neale et al. 2003; Plomin 1990).

\section{Results}

Table 1 displays descriptive statistics for each of the MIDUS religion measures (separately for monozygotic and same-sex dizygotic twins). ${ }^{4}$ From these results, we can see that only slight variations exist between the two types of twins with respect to the means and standard deviations of these religious outcomes. The intrapair correlations, however, reveal that monozygotic twin siblings are more highly correlated with (i.e., similar to) each other on all eight measures compared with dizygotic twin siblings. In some cases these differences are not extremely large, as is the case for childhood religiosity ( 0.73 and 0.60 for monozygotic and dizygotic twins, respectively), but for others such as being born-again or making a religious or spiritual commitment, the difference is quite large ( 0.71 and 0.38 for monozygotic and dizygotic twins, respectively). As described above, larger correlations for monozygotic compared with dizygotic siblings suggests that genetic factors may be important. Thus, these findings preliminarily suggest that genetic factors likely contribute to individual-level variation on all eight religious outcomes examined here. (Note: The correlations for the two dichotomous variables-exclusivist beliefs and being 


\section{TABLE 1 \\ DESCRIPTIVE STATISTICS FOR FOUR DIMENSIONS (EIGHT MEASURES) OF RELIGIOUS INVOLVEMENT}

\begin{tabular}{|c|c|c|c|c|c|c|}
\hline Religion Measures & $N$ (Pairs) & Min-Max & Mean & $S D$ & Covariance & Correlation \\
\hline \multicolumn{7}{|l|}{ Organizational involvement } \\
\hline $\begin{array}{c}\text { Religious or spiritual } \\
\text { service attendance }\end{array}$ & $305 / 266$ & $0-11$ & $2.04 / 2.30$ & $2.23 / 2.40$ & $0.52 / 0.37$ & $0.53 / 0.37$ \\
\hline \multicolumn{7}{|c|}{ Personal religiosity and spirituality } \\
\hline Childhood religiosity & $316 / 278$ & $1-4$ & $3.18 / 3.23$ & $0.85 / 0.80$ & $0.53 / 0.38$ & $0.73 / 0.60$ \\
\hline Religious salience & $306 / 255$ & $6-24$ & $16.69 / 17.17$ & $4.70 / 4.13$ & $14.00 / 7.19$ & $0.63 / 0.42$ \\
\hline Spirituality & $305 / 261$ & $2-8$ & $6.15 / 6.36$ & $1.65 / 1.52$ & $1.39 / 0.73$ & $0.51 / 0.32$ \\
\hline $\begin{array}{l}\text { Daily guidance and } \\
\text { coping }\end{array}$ & $310 / 270$ & $2-8$ & $5.52 / 5.64$ & $2.10 / 2.13$ & $2.57 / 1.64$ & $0.58 / 0.37$ \\
\hline \multicolumn{7}{|l|}{ Conservative ideologies } \\
\hline Biblical literalism & $198 / 177$ & $1-5$ & $3.58 / 3.66$ & $1.42 / 1.38$ & $1.16 / 0.65$ & $0.58 / 0.34$ \\
\hline Exclusivist beliefs & $309 / 267$ & $0-1$ & $0.45 / 0.48$ & $-1-$ & $0.11 / 0.06$ & $0.44 / 0.24$ \\
\hline \multicolumn{7}{|c|}{ Transformations and commitment } \\
\hline $\begin{array}{l}\text { Born-again/religious or } \\
\text { spiritual commitment }\end{array}$ & $193 / 176$ & $0-1$ & $0.56 / 0.55$ & $-1-$ & $0.18 / 0.09$ & $0.71 / 0.38$ \\
\hline
\end{tabular}
attendance.

(a) $N=$ The number of cases remaining after listwise deletion of missing values.

(b) Same for monozygotic and same-sex dizygotic twin pairs (larger numbers represent higher levels of religious involvement).

(c) Twin 1 versus twin 2 separately for monozygotic/same-sex dizygotic twin pairs (all correlations are significant at $p<0.001$ or less).

born-again or making a religious or spiritual commitment—are reported as Pearson's correlation coefficients instead of the more appropriate tetrachoric correlations for two reasons: simplicity, and to be consistent with the other measures. The substantive findings reported here, and below, are virtually identical, however, regardless of the estimation procedure used.)

Turning now to the SEM results, Table 2 shows goodness-of-fit criterion for each of the three models discussed above (one full and two reduced) for each of the eight religion measures separately. According to the $\chi^{2} p$-values and AIC statistics, models containing a genetic component (Columns 1 and 2 under each subheading) fit better for each of the measures than models without this component (Column 3 under each subheading). For religious or spiritual service attendance, a reduced model that includes only shared and nonshared environmental influences also fits the data well, but taking genetic effects into consideration adds to the overall model fit for even this aspect of religious life. For each of the remaining seven measures, however, a genetic factor is required to adequately explain the data.

That said, overall model fit statistics such as $\chi^{2}$ and AIC can sometimes be misleading with respect to the importance of particular parameters in the model (especially for simple models like the ones estimated here), and dropping parameters (significant or not) can lead to biased estimates on the remaining ones (Edwin et al. 2000). Therefore, as an additional check of statistical significance, 95 percent confidence intervals are estimated for each of the three parameters in the full model. Statistically significant paths - that is, those where the confidence intervals do not contain zero-are indicated by stars in Table 3, which shows proportional genetic, shared environmental, and nonshared environmental influences on all of the religious variables. 
TABLE 2

GOODNESS-OF-FIT-CRITERION FOR STRUCTUAL EQUATIONS MODELS FIT TO COVARIANCE MATRICES FOR FOUR DIMENSIONS (EIGHT MEASURES) OF RELIGIOUS INVOLVEMENT

\begin{tabular}{|c|c|c|c|c|}
\hline Religion Measures & Chi-Square & $\begin{array}{c}p \text {-value } \\
\text { (Chi-Square) }\end{array}$ & $\begin{array}{c}\mathrm{df} \\
\text { (Chi-Square) }\end{array}$ & AIC \\
\hline \multicolumn{5}{|l|}{ Organizational involvement } \\
\hline $\begin{array}{c}\text { Religious or spiritual } \\
\text { service attendance }\end{array}$ & $0.04 / 3.72 / 6.86$ & $1.00 / 0.45 / 0.14$ & $3 / 4 / 4$ & $-5.96 /-4.28 /-1.14$ \\
\hline \multicolumn{5}{|c|}{ Personal religiosity and spirituality } \\
\hline Childhood religiosity & $4.52 / 37.66 / 10.64$ & $0.21 / 0.00 / 0.03$ & $3 / 4 / 4$ & $-1.49 / 29.66 / 2.64$ \\
\hline Religious salience & $10.21 / 18.43 / 16.41$ & $0.02 / 0.00 / 0.00$ & $3 / 4 / 4$ & $4.21 / 10.43 / 8.41$ \\
\hline Spirituality & $5.95 / 8.58 / 10.83$ & $0.11 / 0.070 / 0.03$ & $3 / 4 / 4$ & $-0.05 / 0.06 / 2.83$ \\
\hline $\begin{array}{l}\text { Daily guidance and } \\
\text { coping }\end{array}$ & $1.11 / 3.36 / 14.30$ & $0.78 / 0.50 / 0.01$ & $3 / 4 / 4$ & $-4.90 /-4.64 / 6.30$ \\
\hline \multicolumn{5}{|l|}{ Conservative ideologies } \\
\hline Biblical literalism & $0.43 / 1.32 / 9.14$ & $0.94 / 0.86 / 0.06$ & $3 / 4 / 4$ & $-5.57 /-6.68 / 1.14$ \\
\hline Exclusivist beliefs & $0.05 / 0.16 / 8.71$ & $1.00 / 1.00 / 0.07$ & $3 / 4 / 4$ & $-5.95 /-7.84 / 0.71$ \\
\hline \multicolumn{5}{|c|}{ Transformations and commitment } \\
\hline $\begin{array}{c}\text { Born-again/religious or } \\
\text { spiritual commitment }\end{array}$ & $0.03 / 0.21 / 27.71$ & $1.00 / 1.00 / 0.00$ & $3 / 4 / 4$ & $-5.97 /-7.79 / 19.71$ \\
\hline
\end{tabular}

From this table we can see that proportional genetic effects on individual-level religious variation range from 19 percent for childhood religiosity to 65 percent for being born-again or making a religious or spiritual commitment. For all eight measures, the confidence intervals reveal that the genetic factors are statistically significant at $p<0.05$ or less. Specifically, genetic influences are sizable for several commonly employed measures of religion, including religious or spiritual service attendance (32 percent), religious salience ( 27 percent), spirituality ( 29 percent), daily guidance and coping (42 percent), biblical literalism (44 percent), exclusivist beliefs (41 percent), and being born-again or making a religious or spiritual commitment (65 percent). The last finding, which shows a proportional genetic effect that is considerably larger than it is for any of the other measures, is particularly noteworthy. ${ }^{5}$

With respect to shared environmental influences - that is, family-level socialization effects, which represent the only source of similarity among twin siblings except for genetic influencesthe effects shown in Table 3 range from 4 percent for exclusivist beliefs to 53 percent for childhood religiosity. Confidence intervals indicate that the estimates for religious or spiritual service attendance ( 21 percent; $p<0.06$ ), childhood religiosity (53 percent), and religious salience (33 percent) are statistically significant at $p<0.05$ or less, while the ones for spirituality, daily guidance and coping, biblical literalism, exclusivist beliefs, and being born-again or making a religious or spiritual commitment are not.

Nonshared environmental influences, which function to differentiate twin siblings on religious outcomes, range from 28 percent for childhood religiosity to 55 percent for exclusivist beliefs. Importantly, this factor is statistically significant ( $p<0.05$ or less) for all eight outcomes. These numbers represent the proportion of the individual-level variation that cannot be explained by either genetic or family-level socializing forces. It is important to note that nonshared environmental influences are almost always statistically significant in twin models-as 


\section{TABLE 3 \\ PROPORTIONAL GENETIC, SHARED ENVIRONMENTAL, AND NONSHARED ENVIRONMENTAL INFLUENCES ON INDIVIDUAL VARIATION FOR FOUR DIMENSIONS (EIGHT MEASURES) OF RELIGIOUS INVOLVEMENT}

\begin{tabular}{|c|c|c|c|}
\hline Religion Measures & $\begin{array}{l}\text { Proportional } \\
\text { Genetic } \\
\text { Influences }\end{array}$ & $\begin{array}{l}\text { Proportional } \\
\text { Shared } \\
\text { Environmental } \\
\text { Influences }\end{array}$ & $\begin{array}{c}\text { Proportional } \\
\text { Nonshared } \\
\text { Environmental } \\
\text { Influences }\end{array}$ \\
\hline \multicolumn{4}{|l|}{ Organizational involvement } \\
\hline $\begin{array}{l}\text { Religious or spiritual } \\
\text { service attendance }\end{array}$ & $0.32^{*}$ & $0.21^{\mathrm{a}}$ & $0.47^{*}$ \\
\hline \multicolumn{4}{|c|}{ Personal religiosity and spirituality } \\
\hline Childhood religiosity & $0.19^{*}$ & $0.53^{*}$ & $0.28^{*}$ \\
\hline Religious salience & $0.27^{*}$ & $0.33^{*}$ & $0.40^{*}$ \\
\hline Spirituality & $0.29^{*}$ & 0.20 & $0.51^{*}$ \\
\hline $\begin{array}{l}\text { Daily guidance and } \\
\text { coping }\end{array}$ & $0.42^{*}$ & 0.16 & $0.42^{*}$ \\
\hline \multicolumn{4}{|l|}{ Conservative ideologies } \\
\hline Biblical literalism & $0.44^{*}$ & 0.13 & $0.43^{*}$ \\
\hline Exclusivist beliefs & $0.41^{*}$ & 0.04 & $0.55^{*}$ \\
\hline \multicolumn{4}{|c|}{ Transformations and commitment } \\
\hline $\begin{array}{l}\text { Born-again/religious or } \\
\text { spiritual commitment }\end{array}$ & $0.65^{*}$ & 0.06 & $0.29^{*}$ \\
\hline
\end{tabular}

they are here-because siblings rarely, if ever, display identical characteristics on any outcome. Unfortunately, these estimates also contain measurement error, which may be relatively large in this study due to the utilization of several single-item measures.

Overall, these findings demonstrate the utility of a behavior genetic approach for both genebased and social scientific research alike. The aspects of religion that all owe a considerable proportion of their individual variation to genetic effects - that is, spirituality, daily guidance and coping, biblical literalism, exclusivist beliefs, and being born-again or making a religious or spiritual commitment - are the ones that should be expected to be more internally motivated, and thus less responsive to social factors. In contrast, shared environmental influences are important for religious or spiritual service attendance, childhood religiosity, and religious salience: aspects of religious life that are obviously subject to powerful environmental pressures. These findings are intuitive, and their ramifications are discussed in detail below.

\section{Discussion}

This study began by asking: Is individual-level religious variation the product of both genetic and social-environmental influences, and if so, what is the relative contribution of each? An analysis of twin sibling data from the MIDUS suggests that the answer is yes, and that the proportion of each varies depending upon the particular aspect of religious life under investigation. Specifically, genetic effects appear to explain large proportions of the variation on several religious outcomes, including daily guidance and coping (42 percent), conservative religious ideologies (44 percent and 41 percent, respectively, for biblical literalism and exclusivist beliefs), and religious transformations such as being born-again or making a religious or spiritual commitment 
(65 percent). Proportional genetic influences are also sizable for measures of religious or spiritual service attendance (32 percent), religious salience (27 percent), and spirituality ( 29 percent). Shared environmental influences, or family-level social effects, appear to be important for several outcomes as well, explaining 21 percent, 53 percent, and 33 percent of the variation, respectively, on religious or spiritual service attendance, childhood religiosity, and religious salience. Nonshared environmental influences also account for considerable proportions, ranging from 28 percent of the variation on childhood religiosity to 55 percent on exclusivist beliefs. In sum, statistically significant genetic and environmental effects were found for all eight of the religious outcomes examined here. Given these findings, the next question is: What does it mean to say that genetic factors, in addition to social-environmental contexts, influence religious life?

One useful way to think about, and interpret, the findings reported here is to frame them in terms of individual desires versus social constraint. To begin with, genetic influences on "social" outcomes such as religious involvement (as tapped by twin studies) likely represent the manifestation of gene-based, innate predispositions, needs, wants, desires, or motivations, while shared and nonshared environmental influences broadly tap family-level social influences and wider social contexts, respectively. Here, this study draws on the work of Udry (1996; see also Jencks 1980; Guo and Stearns 2002), who suggested: (a) the higher the level of social constraints experienced by individuals in an environment, the more variance is likely controlled by social forces; and (b) conversely, the more opportunities to exercise free-will an individual has, the more variance is likely controlled by genetic factors. In other words, proportionally large genetic effects may reflect the relative weakness of social-environmental influences, whereas smaller genetic effects imply that social influences are particularly powerful. Thus, when behavior genetic techniques are employed to analyze social outcomes such as religion, the genetic component is not seen as "determining" outcomes, but instead appears to tap the ability to think or behave in accordance with one's internal, biological motivations.

When this interpretive framework is applied to the findings reported above, the results are largely supportive. For instance, theory suggests that organization-based religious practices such as service attendance should be subject to social influences or constraints to a greater degree than more private aspects of religion such as beliefs or commitments. In other words, individuals likely alter their outward religious practices (e.g., attendance at services and other organization-based activities) in order to accommodate the wishes of others in part because these expressions of conformity can be monitored and sanctioned (Sherkat 1997), while individuals may be less prone to adopt particular religious beliefs, to draw on religious resources in their everyday lives, or to experience religious transformations or make religious commitments based on external social pressures. These latter aspects of religious life may flow, instead, from internal motivations or desires to a larger degree than their more "social" counterparts. The findings presented above support this idea by showing that proportional genetic influences are relatively smaller (and thus social-environmental ones are comparably larger) on religious attendance (32 percent) compared with conservative beliefs (41-44 percent), religious coping strategies (42 percent), and transformation and commitments (65 percent).

Behavior genetic techniques and twin models like the ones employed here also shed light on family-level socialization effects. Shared environmental influences, as previously discussed, are social processes that function to make individuals who share them more similar to each other. In essence, these are the micro contexts in which theories of social learning argue that the majority of socialization and reinforcement occurs (Carson and Rothstein 1999; D'Onofrio et al. 1999). Although behavior genetic research has seldom found that these environments explain much of the individual variation on diverse attitudes and behaviors (Plomin 1990), they do appear to be important for certain facets of religion, particularly organization-based forms such as religious attendance. In this study, family-level socialization arguments were partially supported - that is, shared environmental influences were found to explain 21 percent, 53 percent, and 33 percent of the individual variation, respectively, on religious or spiritual service 
attendance, childhood religiosity, and religious salience. For these three outcomes, family contexts are obviously important, but for the other aspects of religion examined here, little or no evidence of family-based socialization was found. It should be noted, however, that these findings are based on a sample of adults, and that shared environmental influences tend to become less important (and thus genetic and nonshared environmental ones become relatively more important) as individuals progress through the life course. It is therefore likely that shared environmental influences are of prime importance during the earlier stages of life (i.e., childhood and adolescence), while genetic factors and nonfamily social influences gain more prominence in adulthood and old age (Eaves et al. 2008).

Although this study nicely supplements existing social scientific research on religion (i.e., by examining free-will and family socialization arguments), it also highlights two potential implications for social scientific approaches. First, it is likely that any model of religion that does not consider all three of the components discussed here-genetic, shared environmental, and nonshared environmental influences - will fail to explain a large proportion of the individuallevel variation on religious practices, salience, beliefs, and experiences. This assertion is based on the fact that each of the eight measures of religion examined here appears to be influenced by both genetic and environmental factors. This suggests that traditional sociological models of religious life, which focus exclusively on the latter, may suffer from explanatory power deficiencies, especially when trying to predict individual-level variation on the more internally motivated aspects of religious participation such as beliefs and commitments.

Second, and perhaps equally important, it is possible that genetic factors may be biasing the results of social scientific studies that employ religious variables as predictors of other outcomes (Bouchard and Loehlin 2001; Udry 1995). For example, some scientists (e.g., Sloan, Bagiella, and Powell 1999) have voiced concern that findings showing a connection between religion and health (see Ellison and Levin 1998 for a review) may be spurious due to the failure to control for important covariates, possibly including potential genetic confounders. Currently, we are unable to definitively establish whether religion is a "cause" of other individual and social outcomes, or whether it is simply a "marker" that is tapping some unobserved set of influences, possibly including genetic factors. As is the case with explanatory power deficiencies, this potential challenge to social scientific research varies depending upon which facets of religion are under investigation - that is, this may be a bigger issue for aspects of religious life such as beliefs and commitments that appear to be strongly influenced by genetic factors, compared with affiliation and organization-based activities, which are influenced by genetic differences to a smaller degree. Important topics of scholarship that could be vulnerable to this concern include the relationships between religious involvement and prosocial attitudes and behaviors, family relations, health and well-being, civic engagement, crime and delinquency, and socioeconomic attainment, among others. In order for the growing corpus of literature in these areas to be accepted by important segments of the larger scientific community, researchers will eventually need to show that these associations are not the spurious results of unobserved genetic predispositions. Efforts to address this issue on a large scale will require additional data collection projects that take both religious and potential genetic influences seriously.

Although informative, this study is unable to explain why and how genetic factors influence religious outcomes. Future research should begin addressing these shortcomings by identifying the pathways by which genetic influences forge their way into religious life. One way to achieve this goal is to examine potential mediators - that is, influences that intervene between genetic predispositions and religious outcomes (Jang et al. 2001; Plomin 1990; Scarr and McCartney 1983). For example, it is likely that genetic effects on social outcomes such as religious involvement are indirect via a whole host of personality and interpersonal characteristics, including extraversion, agreeableness, openness to experience, and the ability to form and maintain positive relationships with others, to name just a few (Alford, Funk, and Hibbing 2005; Bradshaw 2007). This 
contention is based on research showing (a) that genetic factors are significant predictors of individual variation on all personality traits, and (b) that these characteristics are, in turn, correlated with religious outcomes (Bouchard and Loehlin 2001; Bouchard et al. 1999; James 1902; Jang, Livesley, and Vernon 1996; Kirkpatrick 1999; Saroglou 2002). In other words, it is likely that genetic effects at least partially function via shaping of individual differences in personality, which then subsequently affect religious life.

To conclude, individual-level variation on a diverse assortment of religious outcomes - that is, service attendance, childhood religiosity, religious salience, spirituality, daily guidance and coping, biblical literalism, exclusivist beliefs, and being born-again or making a religious or spiritual commitment - appears to be the product of both genetic and social-environmental influences. These findings, which are in contrast to most of the published research on religious participation, as well as social scientific theory in general, demonstrate the need to begin integrating genetic and other biological factors into existing theoretical and empirical models of religious life. Behavior genetics, the approach employed here, is capable of doing this, and thus offers the potential to shed new light not only on potential genetic influences, but also on the arguments social scientific theory by addressing the longstanding question: To what extent are innate motivations versus social influences or constraints responsible for the observed variation on religious outcomes? The social scientific study of religion has either much to gain by capitalizing on the strengths of this approach, or much to lose by ignoring them. The next step forward in the multidisciplinary struggle to understand religious phenomena will undoubtedly involve research on the role of genetic and other biological influences, and social scientists should therefore seek to become more involved in this area of scholarship.

\section{ACKNOWLEDGMENTS}

The authors would like to thank Rhys Williams, Maria Davis, Andrea Henderson, and two anonymous reviewers for their comments on previous drafts. We the authors, however, are solely responsible for any arguments, mistakes, or shortcomings.

\section{NoTeS}

1. Although twin studies like this one provide unique insight into religious phenomena, like all techniques, they also suffer from shortcomings and limitations. One of these is the inability to elaborate on the workings of "nongenetic" biological processes. Future research will need to address other potential biological influences.

2. Research using this three-component behavior genetic model has led to an important conclusion, one that may be counterintuitive to some social scientists: "Children growing up in the same family do not usually resemble each other unless they are genetically related" (Plomin 1990:118). Put another way, for most outcomes examined to date (e.g., personality, health, and well-being, etc.), family members, particularly siblings, tend to display similar attitudes and behaviors only to the extent that they share genetic material, not because they reside, or were reared, in the same household. Thus, for a variety of outcomes it appears to be shared genes and not shared family environments that function to make individuals in the same household similar to one another. That said, certain aspects of religion, including service attendance, appear to be rare and important exceptions to this general trend. In other words, religious outcomes are among only a handful of topics in which shared environmental influences show substantial contributions to individual variation.

3. Interestingly, findings on organization-based religious participation suggest that genetic factors may be relatively more important among African Americans compared with whites (Heath et al. 1999). If this finding is replicated, it may serve as a possible explanation for why African Americans tend to be more religious than other racial/ethnic groups (at least in the United States).

4. All of the statistics reported here are calculated for cases that remained after listwise deletion of missing values was performed separately for each measure of religion.

5. There are at least two possible explanations for this finding. First, religious or spiritual transformations could be highly correlated with one or more latent personality traits such as openness to experience. Given that most personality traits are substantially influenced by genetic factors (50 percent or more), if such a correlation does exist, it could explain this 
finding. It is certainly possible that some people are genetically predisposed toward emotion-laden religious or spiritual experiences. Second, although the presence of a genetic effect on this outcome is not really in doubt, the wording of this particular question forces us to interpret this finding with caution (i.e., it combines a generic commitment to Jesus Christ that may be shared among all Christians, with the with the conservative Protestant-specific concept of being "born-again"). The fact that it is a dichotomous variable that fails to fully capture the range of variation on this aspect of religious life could also be an explanation for this finding. Future research should certainly delve deeper into the potential genetic nature of this aspect of religious life.

\section{REFERENCES}

Alford, J. R., C. L. Funk, and J. R. Hibbing. 2005. Are political orientations genetically transmitted? American Political Science Review 99(2):153-67.

Batson, C. D., P. Schoenrade, and W. L. Ventis. 1993. Religion and the individual: A social-psychological perspective. New York: Oxford University Press.

Beer, J. M., R. D. Arnold, and J. C. Loehlin. 1998. Genetic and environmental influences on MMPI factor scales: Joint model fitting to twin and adoption data. Journal of Personality and Social Psychology 74:818-27.

Berger, P. L. 1969. The sacred canopy: Elements of a sociological theory of religion. New York: Doubleday Anchor Books.

Boomsma, D. I., E. J. C. de Geus, G. C. M. van Baal, and J. R. Koopmans. 1999. A religious upbringing reduces the influence of genetic factors on disinhibition: Evidence for interaction between genotype and environment on personality. Twin Research 2(2):115-25.

Bouchard, T. J. Jr. and J. C. Loehlin. 2001. Genes, evolution, and personality. Behavior Genetics 31(3):243-73.

Bouchard, T. J. Jr., M. McGue, D. T. Lykken, and A. Tellegen. 1999. Intrinsic and extrinsic religiousness: Genetic and environmental influences and personality correlates. Twin Research 2(2):88-98.

Bradshaw, M. 2007. Genetic influences on religious involvement: Are they the indirect byproducts of general predispositions toward social interaction. Paper presented at the annual meeting of the Society for the Scientific Study of Religion, Tampa, FL, November 2-4, 2007.

Brim, O. G., P. B. Baltes, L. L. Bumpass, P. D. Cleary, D. L. Featherman, W. R. Hazzard, R. C. Kessler, M. E. Lachman, H. R. Markus, M. G. Marmot, A. S. Rossi, C. D. Ryff, and R. A. Shweder. [1996] 2003. National Survey of Midlife Development in the United States (MIDUS), 1995-1996 [Computer file]. 2nd ICPSR version. Ann Arbor, MI: DataStat, Inc./Boston, MA: Harvard Medical School, Dept. of Health Care Policy [producers], 1996. Ann Arbor, MI: Inter-University Consortium for Political and Social Research [distributor], 2003.

Carson, R. A. and M. A. Rothstein. 1999. Behavioral genetics: The clash of culture and biology. Baltimore, MD: Johns Hopkins University Press.

Cleveland, H. H. and R. Crosnoe. 2004. Individual variation and family-community ties: A behavioral genetic analysis of the intergenerational closure in the lives of adolescents. Journal of Adolescent Research 19(2):174-91.

D’Onofrio, B. M., L. J. Eaves, L. Murrelle, H. H. Maes, and B. Spilka. 1999. Understanding biological and social influences on religious affiliation, attitudes and behavior: A behavior-genetic perspective. Journal of Personality 67(6):953-84.

Eaves, L. J., P. K. Hatemi, E. C. Prom-Womley, and L. Murrelle. 2008. Social and genetic influences on adolescent religious attitudes and practices. Social Forces 86(4):1621-46.

Eaves, L. J., N. G. Martin, and A. C. Heath. 1990. Religious affiliation in twins and their parents: Testing a model of cultural inheritance. Behavior Genetics 20:1-22.

Edwin, J. C. G., V. D. Oord, E. Simonoff, L. J. Eaves, A. Pickles, J. Silberg, and H. Maes. 2000. An evaluation of different approaches for behavior genetic analyses with psychiatric symptom scores. Behavior Genetics 30:1-18.

Ellison, C. G. and J. S. Levin. 1998. The religion-health connection: Evidence, theory, and future directions. Health Education and Behavior 25(6):700-20.

Ellison, C. G. and D. E. Sherkat. 1995. The "semi-involuntary institution" revisited: Regional variations in church participation among black Americans. Social Forces 73(4):1415-37.

Francis, L. J. and L. B. Brown. 1991. The influence of home, church, and school on prayer among sixteen-year-old adolescents in England. Review of Religious Research 33(2):112-22.

Geertz, C. 1973. The interpretation of cultures. New York: Basic Books.

Guo, G. and E. Stearns. 2002. The social influences on the realization of genetic potential for intellectual development. Social Forces 80(3):881-910.

Hayes, B. C. and Y. Pittelkow. 1993. Religious belief, transmission, and the family: An Australian study. Journal of Marriage and the Family 55(3):755-66.

Heath, A. C., P. A. F. Madden, J. D. Grand, T. L. McLaughlin, A. A. Todorov, and K. K. Bucholz. 1999. Resiliency factors protecting against teenage alcohol use and smoking: Influences of religion, religious involvement and values, and ethnicity in the Missouri adolescent female twin study. Twin Research 2(2):145-55. 
Hoge, D. R., G. H. Petrillo, and E. I. Smith. 1982. Transmission of religious and social values from parents to teenage children. Journal of Marriage and the Family 44(3):569-80.

Iannaccone, L. R. 1994. Why strict churches are strong. American Journal of Sociology 99(4):1180-1211.

James, W. 1902. The varieties of religious experience. New York: Modern Library.

Jang, K. L., W. J. Livesley, and P. A. Vernon. 1996. Heritability of the big five personality dimensions and their facets: A twin study. Journal of Personality 64(3):577-91.

Jang, K. L., P. A. Vernon, W. J. Livesley, M. B. Stein, and H. Wolf. 2001. Intra- and extra-familial influences on alcohol and drug misuse: A twin study of gene-environment correlation. Addiction 96(9):1307-18.

Jencks, C. 1980. Heredity, environment, and public policy reconsidered. American Sociological Review 45(5):723-36.

Kendler, K. S., C. O. Gardner, and C. A. Prescott. 1997. Religion, psychopathology, and substance use and abuse: A multimeasure, genetic-epidemiologic study. American Journal of Psychiatry 154(3):322-29.

Kirk, K. M., L. J. Eaves, and N. G. Martin. 1999. Self-transcendence as a measure of spirituality in a sample of older Australian twins. Twin Research 2(2):81-87.

Kirk, K. M., H. H. Maes, A. C. Heath, N. G. Martin, and L. J. Eaves. 1999. Frequency of church attendance in Australia and the United States: Models of family resemblance. Twin Research 2(2):99-107.

Kirkpatrick, L. A. 1999. Toward an evolutionary psychology of religion and personality. Journal of Personality 67(6):92152.

Koenig, L. B., M. McGue, R. F. Krueger, and T. J. Bouchard Jr. 2005. Genetic and environmental influences on religiousness: Findings for retrospective and current religiousness ratings. Journal of Personality 73(2): 471-88.

Loehlin, J. C. and R. C. Nichols. 1976. Heredity, environment, and personality: A study of 850 sets of twins. Austin, TX: University of Texas Press.

Lykken, D. T., T. J. Bouchard, M. McGue, and A. Tellegen. 1990. The Minnesota twin family registry: Some initial findings. Acta Genetica Medica Gemello 39:35-70.

Maes, H. H., M. C. Neale, N. G. Martin, A. C. Heath, and L. J. Eaves. 1999. Religious attendance and frequency of alcohol use: Same genes or same environments: A bivariate extended twin kinship model. Twin Research 2(2): 169-79.

Martin, N. G., L. J. Eaves, A. C. Heath, R. Jardine, L. M. Feingold, and H. J. Eysenck. 1986. Transmission of social attitudes. Proceedings of the National Academy of Sciences of the United States of America 83:4364-68.

Miller, A. S. and R. Stark. 2002. Gender and religiousness: Can socialization explanations be saved? American Journal of Sociology 107(6):1399-1423.

Myers, S. M. 1996. An interactive model of religiosity inheritance: The importance of family context. American Sociological Review 61(4):858-66.

Neale, M. C., S. M. Boker, G. Xie, and H. H. Maes. 2003. Mx: Statistical modeling. 6th Edition. Department of Psychiatry, Medical College of Virginia. Available at http://www.vcu.edu/mx/documentation.html

Neale, M. C. and L. R. Cardon. 1992. Methodology for genetic studies of twins and families. New York: Springer.

Pattillo-McCoy, M. 1998. Church culture as a strategy of action in the black community. American Sociological Review 63(6):767-84.

Plomin, R. 1990. Nature and nurture: An introduction to human behavioral genetics. Stamford, CT: Brooks/Cole Publishing Company.

Plomin, R. and R. Rende. 1991. Human behavioral genetics. Annual Review of Psychology 42:161-90.

Regnerus, M. D., C. Smith, and B. Smith. 2004. Social context in the development of adolescent religiosity. Applied Developmental Science 8:27-38.

Saroglou, V. 2002. Religion and the five factors of personality: A meta-analytic review. Personality and Individual Differences 32:15-25.

Scarr, S. and K. McCartney. 1983. How people make their own environments: A theory of genotype $>$ environment effects. Child Development 54(2):424-35.

Sherkat, D. E. 1997. Embedding religious choices: Integrating preferences and social constraints into rational choice theories of religious behavior. In Rational choice theory and religion: Summary and assessment, edited by L. A. Young, pp. 65-86. New York: Routledge Press.

Sloan, R., E. Bagiella, and T. Powell. 1999. Religion, spirituality, and medicine. Lancet 353(9153):664-67.

Smith, C. 2003. Moral, believing animals: Human personhood and culture. New York: Oxford University Press.

Stark, R. 1996. The rise of Christianity: A sociologist reconsiders history. Princeton, NJ: Princeton University Press.

Stark, R. and W. S. Bainbridge. 1996. A theory of religion. New Brunswick, NJ: Rutgers University Press.

Stark, R. and R. Finke. 2000. Acts of faith: Explaining the human side of religion. Berkeley, CA: University of California Press.

Truett K. R., L. J. Eaves, J. M. Meyer, A. C. Heath, and N. G. Martin. 1992. Religion and education as mediators of attitudes: A multivariate analysis. Behavior Genetics 22:43-62.

Udry, J. R. 1995. Sociology and biology: What biology do sociologists need to know? Social Forces 73(4):1267-78.

- 1996. Biosocial models of low-fertility societies. In Fertility in the United States: New patterns, new theories, edited by J. B. Casterline, R. D. Lee, and K. A. Foote, pp. 325-336. New York: Population Council. 
Waller, N. G., B. A. Kojetin, T. J. Bouchard Jr., D. T. Lykken, and A. Tellegen. 1990. Genetic and environmental influences on religious interests, attitudes, and values: A study of twins reared apart and together. Psychological Science 1(2):138-42.

Winter, T., J. Kaprio, R. J. Viken, S. Karvonen, and R. J. Rose. 1999. Individual differences in adolescent religiosity in Finland: Familial effects are modified by sex and region of residence. Twin Research 2(2):108-14.

Wuthnow, R. 1989. Meaning and moral order: Explorations in cultural analysis. Berkley, CA: University of California Press. 